\title{
Aggression and Violence in Youth and Issue of Delinquency
}

\author{
Poonam Pathak \\ Assistant Professor, Department of Economics, Khalsa College for Women, Ludhiana, India
}

\begin{abstract}
Aggression and violence are the most important issues that modern society is facing. Both the electronic and print media is full of news on violence, crime, murder, rape, child abuse, harassment and so on. The peculiar change that one can notice is the increasing involvement of adolescents in these crimes.No single factor can predict who is likely to engage in violent behaviour, but various studies have established developmental phases that lead to anti-social and delinquent behaviour.Various socio-economical and psychological factors have a great bearing on the young impressionable minds. If not handled on time the young, agile and productive youth will take no time to change into an uncontrollable force that can devastate everything coming in their way.
\end{abstract}

Keywords: Aggression,Violence,Crime, Anti-Social, Delinquent, Youth

\section{Introduction}

Violence by young people is one of the most visible forms of violence in society. Around the world, print and electronic media report daily on violence by gangs, in schools or by young people on the streets. The main victims and perpetrators of such violence, almost everywhere are themselves adolescents and young adults. Youth violence deeply harms not only its victims, but also their families, friends and society as a whole. Its effects are seen not only in deaths, illness and disability, but also in terms of quality of life. Violence involving young people adds greatly to the costs of health and welfare services, reduces productivity, decreases the value of property, disrupts a range of essential services and generally undermines the fabric of society. No single factor can foretell who is likely to indulge in aggressive and violent behaviour. Studies however, have identified development routes that produce anti-social and delinquent behaviour, including patterns of aggression and violence. Hyperactivity, limited attention span, restlessness, risk-taking poor social skills and certain beliefs and attitude are some factors that tend to encourage the development of delinquent behaviour. Also, some persons with a variety of disabilities(e.g. emotional disturbances, attention-deficit, hyperactivity disorders, certain learning disabilities etc.)are more prone to displaying disruptive behaviour, indicating that these conditions may be risk factors for later aggressive and violent actions. Similarly circumstances at home, harsh or inconsistent parental discipline, absence of parental involvement, family discord, parental criminality, child abuse and/or neglect and rejection can also cause anti-social behaviour.These may include lack of school involvement, academic and social failures and inconsistent and inequitable disciplinary practices. Similarly failure to financially support(e.g. friends, employment) may lead to efforts to gain such support through antisocial behaviour. The problem of youth violence cannot be viewed in isolation from other problem behaviours. Violent young people tend to commit a range of crimes. They also often display other problems, such as dropping out of school, substantive abuse, compulsive lying and reckless driving.

Definition of Youth Violence: Violence is threatened or actual physical force or power initiated by an individual that results in or has a high likelihood of resulting in, physical or psychological injury or death. Violence may be a learned behavioural response utilised to achieve an end, or it may be a habitual reflexive way of responding to stressful stimuli. (Youth Violence and Suicide Prevention Team, 1999)

\section{Socio- Economic Causes of Aggression and Violence in Youth}

Adolescence is considered as the most important transition period of life, as adolescents face an intense turmoil because of the cognitive, biological and social changes taking place in this period. It is a period of heightened risk with high rates of conduct disorders and antisocial behaviour. In this stage, any of thwarting of desires,interruption in activities, constant fault finding, teasing,lecturing and making unfavourable comparisons with others lead to aggression,(Veeraraghvan,2006). Present paper is an attempt to review some of the researches conducted to get an idea of certain selected predictors or correlates towards development of aggression and violence among youth.

\section{Peer Pressure}

Teens who are involved in violent activities usually do not perform them alone but in group of friends. Youth abuse, alcohol and drugs, carry guns and enter gangs due to peer pressure. Bullying and eve-teasing are also prevalent among youth. Teenagers are easily influenced by their friends, so if the friends are violent, the chances of your teen becoming violent will increase.

\section{Parental Violence}

If a teen's parents are abusive, violent or portray hostile behaviour to each other, to the teen or to others outside the family, there is likely chance the teen will display similar or worse behaviour.Witnessing violence in the home or being physically or sexually abused, conditions children and adolescents to regard violence as acceptable means of resolving problems.

\section{Media Exposure}

Over the past two decades, hundreds of studies have examined how violent programmes on T.V effects children and young people. While a direct cause and effect link is 


\section{International Journal of Science and Research (IJSR) \\ ISSN (Online): 2319-7064 \\ Index Copernicus Value (2013): 6.14 | Impact Factor (2015): 6.391}

difficult to establish, there is a growing consensus that some adolescents may be vulnerable to violent images and messages. Boys who watched more aggression and violence on television were the most likely to commit a crime, be aggressive in sports, threaten violence towards another boy, or to break windows(Belson 1978). Violence in the media helps promote and encourage children and adolescents to freely express their abusive behaviour.

\section{Poor Mental Health}

Long-term stressful situations can produce a lasting, lowlevel stress that is hard on people. The nervous system senses continued pressure and may remain slightly activated and continue to pump out extra stress hormones over an extended period (Miczek). This can wear out the body's reserves, leave a person feeling depleted or depressed. This leads to very serious disorders especially in young age such as, irritability, depression, aggression, anxiety and obsessive-compulsive disorder.

\section{Nebiourhood Causes}

The communities in which young people live are an important influence on their families, peer groups and the way they may be exposed to situations that leads to violence. Those living in neighbourhoods with high level of crime, all the more are likely to be involved in violent behaviour than those living in other neighbourhoods. The presence of gangs, guns and drugs in a locality increase the violent behaviour.

\section{Failure}

Academic pressures in this stage worry adolescents a lot. Fear of low scores, fear and concern about future career, failure in examinations etc. are of main concerns. There is lack of motivation to do well, problems at home or with peers, poor work habits or study skills, emotional and behavioural problems. Doing low in academic fields leads to problems with low self-esteem, behaviour problems and depression. Teens who are under academic pressures may experience lack of self-confidence, fear of unhealthy comparisons from parents and relatives and lack of communication from peers and society at large. In the modern fast paced life where harder tasks need to be accomplished in shorter time, adolescents feel pressured to perform, to fit in, leading to a lot of unrest which further leads to frustration and ultimately to aggression.

\section{Being Victimised}

The children who are being bullied or victimised themselves show aggressivebehaviour. The relationship between being abused as a child and becoming abusive towards others as an adult is known as the "cycle of violence"hypothesis which infers that victims of violence become perpetrators of violence. For example, the youth who grew up in violent homes report more violence towards their partners in intimate relationships (Wolfe et al ,2001).

\section{Economic and Social Diseqilibrium}

The dis-equilibrated economic and social system provides necessary pre-requisite for violence. The existence of economic and social dualism with the society divided in two segments of haves and have not's, unrest is inevitable. The youth from the lower economic strata envy their counterparts from the upper economic strata which leads to unrest and hopelessness.In their pursuit of enjoying reasonable life-style, they don't shy away in doing any act of violence that could make them better off. The Naxal phenomenon could be better explained in the socioeconomic paradigm. When the goals of equality, liberty and human rights and progress are denied to tribals and dalits, they are left with no other option except to resort to means of violence to reach their goals. Socio - economic status of family is an important factor which contributes to the behavioural development. Economic hardships produce frustration that affectsadolescents. Adolescents of lower class family cannot fulfil their needs and are greatly restricted in all phases of their lives. The consequence is that all forms of aggression become more commonin them. Aggression among children from a poor socio- economic background is a means for survival.But on the other hand experts warn that social changes unleashed, that urban families are just cracking under the pressure. When liberalization happened, many parents went over-board, giving their children everything they had missed . At first it was voluntary, but now kids and adolescents have started taking advantage of their parents overindulgence and parents aren't in a position to pull back. Any of the thwarting of adolescents desires and interruption in their activities results in aggressive outbursts (Sharma, 2008). Boys from low economic status were rated as physically aggressive by Janna et al,( 1994) after studying family background and prediction of delinquency of physically aggressive boys Kupersmith et al (1995) studied childhood aggression and peer relation in the context of family and neighbourhood. They found that middle economic status operated as a protective factor for reducing aggression among respondents. Mathur(2004) reported that aversive conditions of lower class life are important determinants of high rates of aggression. The restricting and controlling behaviour of parents is many time frustrating for the child and may culminate in aggression by the child.

\section{Aggression and Delinquency}

Juvenile delinquency is a term that is commonly used to denote offences committed by children and adolescents. Technically it is a legal term that refers to single or multiple acts that violate the law by person who are minors, generally under age 18 (Agnew, 2005). Delinquency is a common manifestation of the developmental process. Though delinquent acts are generally transitory and episodic, with most youths indulging in petty misbehaviour, some youth may engage in repetitive and serious delinquent acts. Investigators differentiate between primarily three categories of delinquency.

1) Socialised delinquency: It includes crimes which are motivated by a desire to conform to the norms of a gang, rather than by deep rooted anxieties or unsolved conflicts.

2) Neurotic delinquency: Delinquents in this category are generally from a middle class background and tend to suffer from anxiety, insecurity and guilt. They commit their crimes alone and often the pattern of criminality continues into adult life.

3) Psychopathic delinquency: It is the most serious form committed by those who are unable to establish lasting 


\section{International Journal of Science and Research (IJSR) \\ ISSN (Online): 2319-7064}

Index Copernicus Value (2013): 6.14 | Impact Factor (2015): 6.391

relationships and who experience a total lack of guilt or remorse for their crimes.

\section{Juvenile Crime Statistics}

According to NCRB data for 2011, 64\% of all juvenile criminals are in the age group of 16-18. A total of 33,887 juveniles were apprehended during 2011 out of which 31,909 were boys and 1,978 were girls. In 2011, 33,887 juvenile were arrested for 25,178 instances of crime. Of these, 1,211 juveniles are in the age group of 7-12 years, 11,019 fall in the $12-16$ years age group while 21,657 fall in the in the 16-18 years age group. In Delhi itself, of the 925 boys arrested for juvenile crimes in 2011, 567 were in the 16-18 years age group. The states of Madhya Pradesh (19.9\%), Maharashtra (19\%), Chhattisgarh (8.7\%), Andhra Pradesh $(7.3 \%)$, Rajasthan $(7.3 \%)$ and Gujarat $(6.4 \%)$ have reported high incidence of juvenile crimes under IPC. Out of the total 888 juvenile murder cases reported in the country in 2011, Maharashtra and Madhya Pradesh reported 16.3\% and $12.6 \%$ cases. The highest incidence of the juvenile rape cases in the country was reported from Madhya Pradesh (23.6\%) followed by Uttar Pradesh (12.7\%) and Maharashtra $(10.9 \%)$ in the country. The highest incidence of the juvenile cases under Special Local Laws was reported from Tamil Nadu (672) which accounted for $23.7 \%$ of total juvenile crimes under SLL followed by Chhattisgarh (514, $18.1 \%)$, Gujarat (464, 16.4\%), Maharashtra (296 cases, $10.4 \%$ ) and Madhya Pradesh (276 cases, 9.7\%). These five states taken together have accounted for $78.3 \%$ of total juvenile delinquency cases under SLL reported in the country (NCRB, 2011).

\section{Conclusion}

Adolescence is a time in which youth seek autonomy and theirownidentity. Some adolescents engage in activities that both are criminal and a risk to their well-being.Violence and aggression are the most vital issues which modern society faces. Despite, wide spread education, independence, freedom of thought and speech, freedom from deprivation, fulfilment of basic needs and wants and improvement in socio-economic conditions and living standards, in many countries around the globe, aggression and violence are on the rise. Youth violence and aggression is a complex problem having its social, economic and psychological aspects. The need of the hour is to understand the underlying causes of youth violence and address these sensitive issues with utmost urgency. Efforts are required on the part of the family, education institutions and society as a whole to provide secure environment to our youth and channelize youth power towards nation building.

\section{References}

[1] Angew, R (2005), Juvenile Delinquency: Causes and Control: Los Angeles, CA:Roxbury.

[2] Baron,R.A,\&Richardson, D,(1994), Human Aggression New York:Plenum Press.

[3] Belson M \& Phillip R Newman(1978) Infancy and childhood, INC: New Jersey.
[4] Jaana H and Richard E(1994)Physically aggressive boys from 6-12 years: Family background, parenting behaviour and prediction of delinquency.Counselling and Clinical Psychology 62(2): 1044-54.

[5] Kupersmith J A, GriseslerP C, Dchossier M E, Peterson C J and Davis P W(1995) Childhood aggression and peer relations in context of family and neighbourhood factors, Child Dev 66(2): 360-75.

[6] Mathur R A (2004) The control of human aggressionAn optimistic perspective, Social and Clinical Psychology 40: 97-119.

[7] Miczaek, K. A,etal,Alcohal, drug abuse, aggression and violence.

[8] NCRB - 2011

[9] Sharma A(2008), Who Let the Kids out? Out Look, June23, 2008. Pp,39-42.

[10] Wolfe, D.A,Scott,K,Wekerle, c,andPitttman,A(2001). Child maltreatment:Risk of adjustment problems and dating violence in adolescents : Journal of the American Academy of Child and Adolescent Psychiatry ,4o, 282-298.

[11] Youth Violence and Suicide Prevention Team, 1999. 